\title{
Adiposis dolorosa of scalp presenting with severe headache: an unusual case
}

\author{
Juhi Kawale $\cdot$ Amit Mahore $\cdot$ Nitin Dange $\cdot$ \\ Kalpesh Bhoyar
}

Received: 29 May 2010/Accepted: 16 August 2010/Published online: 2 September 2010

(C) Springer-Verlag 2010

\begin{abstract}
A 46-year-old female, known case of adiposis dolorosa since adolescence, noticed painful thickening of scalp in bilateral parieto-occipital areas and vertex 1 year back. Six weeks prior to the presentation to our service, she developed severe occipital headache refractory to drug treatment. She improved after bilateral greater occipital nerve blocks. She was subjected to bilateral greater occipital chemical neurolysis which has given her complete pain relief.
\end{abstract}

Keywords Adiposis dolorosa - Painful lipoma .

Headache - Greater occipital nerve block

\section{Introduction}

The clinical picture of adiposis dolorosa makes a lasting impression on the examining clinician. Adiposis dolorosa is a disease characterized by painful subcutaneous fatty tumors. This disorder has been described to occur commonly in obese, post-menopausal women and is associated

\section{J. Kawale}

Department of Medicine, King Edward Memorial Hospital and Seth Gordhandas Sunderdas Medical College,

Parel, Mumbai, India

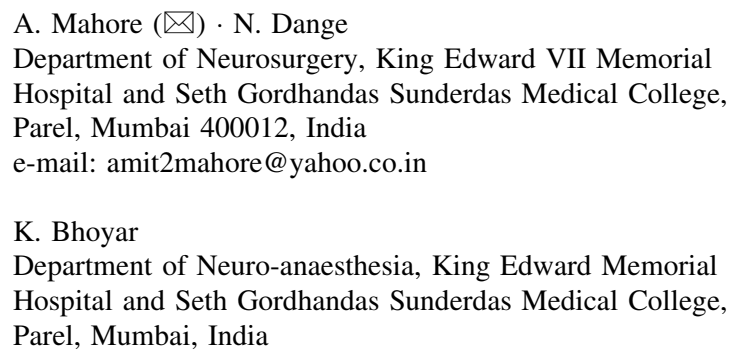

with weakness and mental disturbances such as depression, confusion, lethargy, and dementia [1]. However, it begins in most cases prior to the post-menopausal period and can also occur in men $[2,3]$. The cause is unknown, and there is no specific treatment $[1,2]$. This case is reportable because adiposis dolorosa is thought to occur primarily on the body and not the head $[4,5]$, but our patient had involvement of scalp with severe headache.

\section{Case report}

A 46-year-old woman noticed painful thickening of the scalp in bilateral parieto-occipital areas and vertex while combing hair for 1 year. Six weeks prior to the presentation to our service, she developed intermittent severe shooting pain in the occipital region of scalp which used to get aggravated on lying supine or pressure on occiput, which compelled the patient to sleep in lateral or prone position. The frequency and severity of pain increased to an extent to disturb sleep and daily activities. Patient had multiple small, subcutaneous fatty lumps all over the body which started painlessly in adolescence; few of them had slightly enlarged with tenderness on palpation, whereas few subcutaneous lumps had spontaneous pain of mild intensity without affecting sleep or daily activities. Computerized tomography (CT) and magnetic resonance imaging (MRI) scan of head revealed diffuse thickening of scalp tissue in vertex and bilateral parieto-occipital areas suggestive of diffuse lipomatosis of scalp with no evidence of intracranial/spinal abnormality of cervical region (Fig. 1a-c). The patient was put on tricyclic antidepressants and multiple analgesics by referring physician, which produced no relief. She was referred to our department when she developed acid peptic disorder due to pain killers. The 

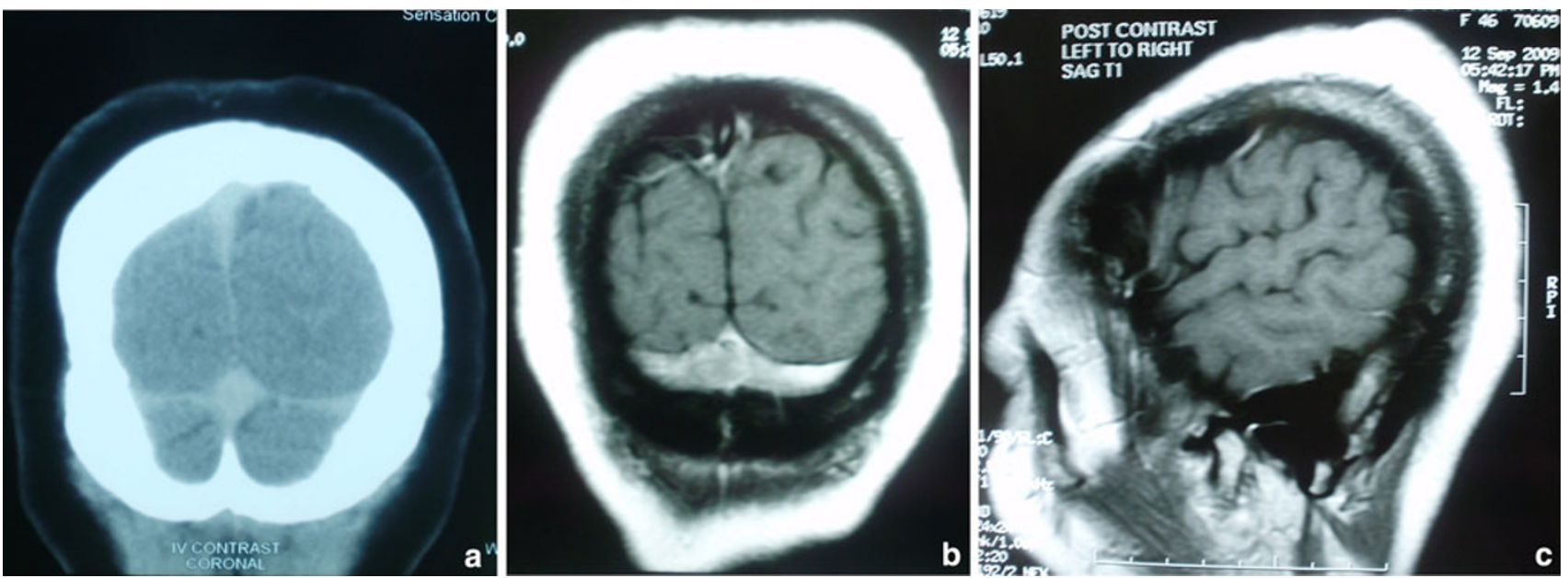

Fig. 1 a Coronal image of CT scan of brain suggestive of abnormal increased thickening of scalp. b Coronal image of MRI scan of brain suggestive of lipomatous thickening of scalp. c Sagital image of MRI scan of brain suggestive of lipomatous thickening of scalp

patient was subjected to psychiatry and neurology evaluation to rule out other causes of headache. Her endocrinological workup was normal. The patient underwent bilateral greater occipital nerve blocks. The nerve was identified under the scalp by palpation. Typical pain or headache was reproduced with pressure over the nerves. Two $\mathrm{ml}$ of $0.5 \%$ bupivacaine was injected to each site, which were approximately $2 \mathrm{~cm}$ lateral and $1 \mathrm{~cm}$ inferior to the external occipital protuberance, just medial to the occipital artery. The injection site was then massaged to spread the solution. The pain resolved completely, within 10 min after the block, but the patient had recurrence of headache after few hours. The blocks were repeated next day, which produced similar results. Therefore, we advised her bilateral surgical greater occipital neurectomy, but she did not give consent. However, she was ready for chemical neurolysis. The procedure was repeated at same sites with injection of $1 \mathrm{ml}$ of $0.5 \%$ bupivacaine followed by $1 \mathrm{ml}$ of 95\% ethyl alcohol after $10 \mathrm{~min}$ to each site, because injection of alcohol alone might be very painful. Massage was not done to prevent fat necrosis due to spread of alcohol along the rest of the scalp. Surprisingly this has produced lasting relief of pain. At 9 months of follow-up, scalp thickening persisted without signs of further progression in size and tenderness. The patient developed hypoesthesia of occipital region which she readily accepts at cost of pain relief. The patient has also developed tiny patches of alopecia at injection sites which is easily hidden in her hair.

\section{Discussion}

Adiposis dolorosa is a disease of unusual distribution of fatty tumors in which the patient is easily dismissed as a malingerer, as pain in these tumors seems out of proportion to the physical findings. Pain may be relieved by steroids, intravenous lidocaine, or analgesics [1,2]. Surgical treatment consists of excision or liposuction of the painful masses in drug refractory cases [6].

Diffuse Dercum's disease of scalp is difficult to treat as other causes of headache and psychological factors have to be ruled out. These lesions cannot be treated by liposuction or excision of mass unlike other body parts [6]. We believe that severe headache in our patient may be caused by pressure over the greater occipital nerves due to abnormally increased fat content in scalp. Ethyl alcohol produced the pain relief by local destruction of axons. The greater occipital nerve (GON) block has been described to be effective in treatment of cluster headache, cervicogenic headache occipital neuralgia and post lumbar puncture headache [7-10]. It is technically easy to perform and has a low incidence of neurological complications. This is a simple, outpatient procedure and can be repeated depending upon the recurrence of pain [9]. We did chemical neurectomy in our patient as intractable pain dramatically responded to bilateral GON blocks and the patient did not give consent for surgical neurectomy. Our patient is under close follow-up for recurrence of symptoms. We did not find similar case report in English literature.

Chemical neurolysis has been used in the treatment of severe or intractable pain associated with cancer, trigeminal or post herpetic neuralgia and Morton's neuroma [1114]; however, its use in adiposis dolorosa has not been reported. We believe that it may be considered by a pain clinician when the drug refractory intractable pain is confined along a specific superficial sensory nerve territory. It should be preceded by successful response to injection of local anesthetic agent [13]. Patient should be explained about the potential risk of permanent hypoaesthesia and 
local tissue necrosis. Larger numbers of such cases are required to establish the efficacy of procedure.

\section{Conclusion}

Adiposis dolorosa of scalp may present with drug refractory localized headache. Chemical neurolysis of nerve in the territory of headache may be considered a treatment modality for lasting relief.

Acknowledgments The authors acknowledge with gratitude, the encouragement and support of Prof. Atul Goel, Head of the Department of Neurosurgery, KEM Hospital, Mumbai, India.

Conflict of interest None.

\section{References}

1. Wortham NC, Tomlinson IP (2005) Dercum's disease. Skinmed 4(3):157-162 quiz 163-164

2. Herbst KL, Asare-Bediako S (2007) Adiposis Dolorosa is More than Painful Fat. The Endocrinologist 17:326-334

3. Danilov LN (1978) Case of Dercum's disease in a 10-year-old child. Pediatriia (1):76-77
4. Dercum FX (1888) A subcutaneous connective-tissue dystrophy of the arms and back, associated with symptoms resembling myxoedema. Univ Med Mag Phila 1:140-150

5. Campen RB, Sang CN, Duncan LM (2006) Case records of the Massachusetts General Hospital: case 25-2006: a 41-year-old woman with painful subcutaneous nodules. N Engl J Med 355: 714-722

6. Berenguer B, de La Cruz L, de La Plaza R (2000) Liposuction in atypical cases. Aesthet Plast Surg 24(1):13-21

7. Bogduk N (1982) The clinical anatomy of the cervical dorsal rami. Spine 7:319-330

8. Peres MFP, Stiles MA, Siow HC, Rozen TD, Young WB, Silberstein SD (2002) Greater occipital nerve blockade for cluster headache. Cephalalgia 22:520-522

9. Tobin J, Flitman S (2009) Occipital nerve blocks: When and what to inject? Headache 49:1521-1533

10. Matute E, Bonilla S, Girones A, Planas A (2008) Bilateral greater occipital nerve block for post-dural puncture headache. Anaesthesia 63:551-560

11. Koyyalagunta D, Burton AW (2010) The role of chemical neurolysis in cancer pain. Curr Pain Headache Rep 14(4):261-267

12. Day M (2001) Neurolysis of the trigeminal and sphenopalatine ganglions. Pain Pract 1(2):171-182

13. Lauretti GR, Trevelin WR, Frade LC, Lima IC (2004) Spinal alcohol neurolysis for intractable thoracic postherpetic neuralgia after test bupivacaine spinal analgesia. Anesthesiology 101(1): 244-247

14. Magnan B, Marangon A, Frigo A, Bartolozzi P (2005) Local phenol injection in the treatment of interdigital neuritis of the foot (Morton's neuroma). Chir Organi Mov 90(4):371-377 